\title{
Interactive comment on "Chemical Characteristics of Marine Fine Aerosols over Sea and at Offshore Islands during Three Cruise Sampling Campaigns in the Taiwan Strait- Sea Salts and Anthropogenic Particles" by Tsung-Chang Li et al.
}

Tsung-Chang Li et al.

ycsngi@mail.nsysu.edu.tw

Received and published: 16 November 2016

\section{Referee comment 1}

(1)Uncertainty analyses are presented in section 2.3 but not detailed enough. The concentrations reported from filter samples involve various sources of uncertainty: uncertainties of flows, weighing, positive and negative artifacts, chemical analysis uncertainties, blank values, blank variability, detection limits, are different for different species. These should be discussed and given numerical values. A table within Section 2.3 showing the concentrations (including gravimetric mass) of the analyzed species in the 
field blanks should be given.

»Thanks for the comment. The results of QA/QC have been summarized in Table 1 per request. (see P25).

(2) Concentrations and mass balances are not properly presented in the paper. There should at least be a table or tables showing statistics of the concentrations of ions, trace elements and carbonaceous component and the percentages of the gravimetric mass. Now it is not possible to find out whether there was some mass missing compared to the gravimetric mass or whether the sum of species was higher than it. The Al concentration can be used for estimating the crustal mass from $\sim 12 \times \mathrm{Al}$ (measured) since the ratio of $\mathrm{Al}$ to other elements in the Earth's crust is relatively constant, see for instance Wedepohl: Geochimica et cosmochimica Acta, 59(7), 1217-1232, 1995.

» Thanks for the comment. We have revised Table 3 per request (see Table 3, P27). Moreover, we have also added a Section of "3.5 Reconstruction of PM2.5 over Sea and at the Offshore Islands," per request. PM2.5 was estimated by material balance equation for gravimetric mass (Chow et al., 1996). In this study, PM2.5 was summed by nine major chemical compositions: nitrate (NO3-), sulfate (SO42-), ammonium $(\mathrm{NH} 4+)$, chloride $(\mathrm{Cl}-)$, organic matter $(\mathrm{OM})$, elemental carbon $(\mathrm{EC})$, crustal materials (CM), sea salt, and others. Organic material (OM) was estimated from an organic carbon $(\mathrm{OC})$ multiplier $(\mathrm{f})$ that accounts for unmeasured hydrogen $(\mathrm{H})$, oxygen $(\mathrm{O})$, nitrogen $(\mathrm{N})$, and sulfur $(\mathrm{S})$ in organic compounds (Chow et al., 1996). Multipliers of 1.4 to 1.8 have been found to best represent the complex mixture of organic molecules in OM (POM) (Chow et al., 1996). A factor of 1.6 for converting OC to OM was used in this study. Crustal materials can be estimated using a method reported by Wedepohl (1995) (Crustal materials $=12^{*}[\mathrm{Al}]$ ), while sea salt was estimated by equation (3). Therefore, PM2.5 concentrations were reconstructed by the following equation,

Table 8 compares the major chemical components of PM2.5 at the coastal sites around the Taiwan Strait and East China Sea. Consistent with previous studies, organic ma- 
terials (OM), SO42-, NO3-, and crustal materials (CM) were the major components for the reconstruction of PM2.5 concentration. The results indicated that SO42-, NO3, crustal materials, and organic materials are important components in PM2.5 at all coastal sites. The contribution of SO42-, NO3-, and organic materials were similar to other coastal sites. (see P15, L17- L31).

(3) The use of "sea salts" in plural is a bit disturbing, in most cases it would be better to use the singular form "sea salt".

» Thanks for the comment. We have replaced "sea salts" with "sea salt" throughout the entire manuscript per request.

(4) The ion data should be used for calculating something more than only chloride depletion. For instance ion balances by using the ion concentrations you would see whether the samples were acidic, alkaline or neutral. The ion data could be used for calculating enrichment factors enrichment factors compared to seawater composition and the trace element data for calculating enrichment factors compared to average crustal rock composition (for example Duce, et al. 1975, Science $10: 59-61$, Artaxo et al. 1992, Tellus B, 44: 318-334.; Wedepohl: Geochimica et cosmochimica Acta, 59(7), 1217-1232, 1995; Mishra et al, 2004, Atm.Env. 38, 4069-4084; etc. ).

» Thanks for the comments. The ionic balance (i.e. A/C) of ionic species ranged from 0.7 to1.0, including that PM2.5 were acidic particles. (see Table 3, P27 and P9, L2829). In previous studies, the particle-induced X-ray emission or proton-induced X-ray emission (PIXE) was used to determine the elemental characteristics of atmospheric particles (Artaxo et al. 1992). In this study, we analyzed ionic species and metallic content by IC and ICP-AES. Comparing different methods for analyzing chemical composition is difficult to calculate the enrichment factors of ionic species (e.g. Cl-), respectively. In this study, same methods were applied to analyze PM2.5 samples collected at the target region, which should be comparable for the enrichment factors of PM2.5 over sea and at the offshore islands. Thus, we used the presence of certain

Printer-friendly version

Discussion paper 
metallic elements in aerosols surrounding the Taiwan Strait primarily due to natural or anthropogenic processes in the target regions. (see P16, L1-L10). Additionally, we have added a Section of "3.6 Enrichment Factors of PM2.5 over Sea and at the Offshore Islands," per request. The EF values of metallic elements in PM2.5 over sea and at the offshore islands are depicted in Figure 6. The order of the EF values for various metallic elements had quite similar trend no matter where atmospheric PM2.5 were sampled. For least ten measured metallic elements, their EF values were in the range of 0.1 to 10000 and highly relevant. Trace elements $\mathrm{Ni}$ and $\mathrm{Cr}$ were highly enriched $(100<E F<10000)$ in $\mathrm{PM} 2.5$, while $\mathrm{Mn}$ and $\mathrm{Pb}$ were moderately enriched $(10<\mathrm{EF}<100)$ at all sites around the Taiwan Strait. Previous studies reported that metallic elements with EF>10 have an important proportion of non-crustal sources and that a variety of emission sources could contribute to their loading in the ambient air. The EF values of crustal elements $\mathrm{Mg}, \mathrm{K}, \mathrm{Ca}$, and Fe in PM2.5 ranged from 1 to 10 over sea and at the offshore islands, and their EF values were quite consistent for fine particles sampled at different sites. It suggested that these crustal elements were likely originated from same natural sources and had no enrichment in PM2.5. In comparison, high EF values of $\mathrm{Ni}, \mathrm{Cr}, \mathrm{Mn}$, and $\mathrm{Pb}$ in the range of 10-10000 suggested that these trace elements were mainly originated from anthropogenic sources. Previous study reported that metallic elements $\mathrm{Cr}$ and $\mathrm{Ni}$ in PM2.5 were mainly from anthropogenic combustion sources, while $\mathrm{Cr}$ and $\mathrm{Ni}$ in PM2.5-10 had more soil-related origins (Chow et al., 1995). (see P16, L16-L27).

(5) Source area analysis would definitely be needed for this kind of a work. At least using air mass back trajectories or footprints with some meteorological model. Such are available and easy to use, for instance the HYSPLIT of NOAA can be used openly and it provides both back trajectories and dispersion modeling.

Printer-friendly version

» Thanks for the comments. In order to identify the predominant sources of air pollutants, backward trajectory has been widely used to trace the transport routes of air masses (Li et al., 2016) (see P7, L4-L6). Previous study reported that the level of at- 
mospheric PM2.5 is affected by meteorological condition, thus PM2.5 concentrations in spring and winter was much higher than those in fall and summer in the Taiwan Strait ( $\mathrm{Li}$ et al., 2016b). However, the results of backward trajectory analysis were not shown in this manuscript. Our previous study indicated that the corresponding trajectories were clustered into three major transport routes according to their airflow directions and regions through which air masses traveled toward the Taiwan Strait ( $\mathrm{Li}$ et al., 2016b). During the consecutive courses in the winter of 2013 (W3), air masses originated from Mongolia were transported across the northern, central, and southeastern China. During the consecutive courses in the spring of 2014 (S14), air masses originated from northern and northeastern China were transported through the coastal regions of central China, East China Sea, and southeastern China toward the Taiwan Strait. During the consecutive courses in the winter of 2014 (W14), air masses originated from northern and northeastern China are transported through the coastal regions of central and southeastern China toward the Taiwan Strait. Results from backward trajectories showed that the concentrations of PM2.5 blown from the north were generally higher than those from the south. PM2.5 samples were collected over sea and at the offshore site during the high pollution seasons in this study. In this study, 72 hour backward trajectories ending at the Penghu Islands at the altitudes of 100, 350, and $500 \mathrm{~m}$ above sea level, respectively, were simulated to represent air masses toward the Taiwan Strait. Air masses originated from Mongolia were transported through northern and central China, and finally across the East China Sea to the offshore site during the three sampling cruises. The results indicated that anthropogenic chemical species were evenly dispersed over sea for the same trajectory during the air pollution episodes, causing the carbonaceous species stably distributed over sea and at the offshore site. (see Section 2.4, P7, L11-15, and Section 3.2, P8, L17-P9, L8).

(6) They should be used to analyze what kind of concentrations or concentration ratios or other derived properties - for instance ion balances by using all ions and ammonium to nss-sulfate ratios, or enrichment factors of trace elements, or OC-to-EC ratios or EC contributions - are associated with air masses from the different source areas. 
» Thanks for the comments. We have added a Section of "3.4 Distribution and Source Indicators of PM2.5 Chemical Composition over Sea and at the Offshore Islands," to describe the distribution of the mass percentage of chemical composition of PM2.5 over sea and on the offshore islands. The results of the distribution percentage of chemical characteristics to PM2.5 during the three courses over Taiwan Strait indicated that water-soluble ionic species, metallic elements, and carbonaceous content accounted for $46.1-52.0 \%, 14.7-19.3 \%$, and $14.0-19.9 \%$ of $\mathrm{PM} 2.5$ during the sampling courses in the winter of 2013 , respectively; $44.4-54.1 \%, 13.1-15.7 \%$, and $13.3-17.9 \%$ during the sampling courses in the spring of 2014 , respectively; $42.7-45.8 \%, 12.3-13.4 \%$, and $15.2-18.8 \%$ during the sampling courses in the winter of 2014 , respectively. The results indicated that the distribution of water-soluble ionic species and carbonaceous contents on the offshore islands were generally higher than those over sea. Previous study reported that the emissions of huge amounts of particulates from various sources (e.g., textile plants at the Jinjing River Basin) could result in the higher percentages of ionic and carbonaceous contents at the Taiwan Strait ( $\mathrm{Li}$ et al., 2016a). The results were close to those at the Penghu site located at an offshore island. (see P14, L18L28) There are several ratios of chemical species can be used as valuable indicators to appoint atmospheric particles from specific sources (Cao et al., 2012; Arimoto et al., 1992). Previous researches reported that the mass ratios of EC/TC, K+/TC, and TC/SO42- can be used to identify the sources from biomass burning (VanCuren, 2013). When the mass ratio of EC/TC ranges from 0.1 to $0.2, \mathrm{~K}+/ \mathrm{TC}$ ranges from 0.5 to 1.0, and TC/SO42- ranges from 6 to 15, it suggests that the sources were mainly contributed from biomass burning (VanCuren, 2013). The mass ratios of NO3-/nssSO42- have also been used to evaluate the contributions from stationary and mobile sources (Arimoto et al., 1992). The mass ratios of NO3-/nss-SO42- higher than unity indicated that the sources of particles were mainly from mobile sources. Conversely, the mass ratios of NO3-/nss-SO42- lower than unity suggested that the sources of particles came mainly from stationary sources. Table 7 compares the mass ratios of major chemical species over sea and at the offshore islands. The mass ratios of 
$\mathrm{EC} / \mathrm{TC}, \mathrm{K}+/ \mathrm{TC}$, NO3-/nss-SO42-, and TC/SO42- during the three courses over Taiwan Strait ranged from $0.28 \pm 0.01$ to $0.30 \pm 0.02$ in the winter of 2013 (W13), $0.10 \pm .02$ to $0.17 \pm .05,0.66 \pm 0.05$ to $0.71 \pm 0.03$ in the spring of 2014 (S14), and $0.94 \pm 0.05$ to $1.18 \pm 0.08$ in the winter of 2014 (W14), respectively, while similar trends reported at the southeastern coastline of the Taiwan Strait ( $\mathrm{Li}$ et al., 2016a). Previous studies reported that high SO42- and NO3- concentrations observed at the Penghu site and the Kaohsiung site were mainly from stationary sources due to burgeoning industrial development in the southwestern coastal region of Taiwan (Tsai et al., 2011; Li et al., 2016a). According to the reports from VanCuren (2003), atmospheric aerosols with high nss-SO42-/NO3- ratios were attributed mainly from stationary sources. (see P14, L21-P15, L16). Moreover, the mass concentrations of PM2.5 and their water-soluble ionic species, metallic elements, and carbonaceous contents for clustered air mass trajectories toward the Taiwan Strait have been discussed and reported in our previous literature (Li et al., 2016b).

Detailed Comments (7) P3, L12. Write the manufacturer, type and model of the sampler. Also the filter type, filter manufacturer and other details, including diameter. The sampler was a high-volume one. What was the flow rate?

» Thanks for the comment. The high-volume air sampler (TE-6001) was used to collect PM2.5 with a sampling flow rate of $1.47 \mathrm{~m} 3 / \mathrm{min}$ passing through a PM2.5 selective inlet. As the particulates travel through the PM10 size selective inlet the larger particulates are trapped inside of the inlet as the smaller PM2.5 particulates continue to travel through the inlet and are collected on the 8" x 10 " quartz fiber filter manufactured by Pall Corporation. This method was complied with the sampling method of NIEA A102.12A similar to USEPA Method IO-2.1. Quartz fiber filter was selected for this study because we conducted the chemical analysis of water-soluble ions, metallic elements, and carbonaceous content. Before weighing, the quartz fiber filters were conditioned in a desiccator at temperatures of $20-25^{\circ} \mathrm{C}$ and relative humidity $(\mathrm{RH})$ of $35-45 \%$ for 48 hours (see Section 2.3, P6, L6- L13).

Printer-friendly version

Discussion paper
Interactive

comment 
(8) P3, L15: ".... we weighted the mass concentrations of both PM2.5 and PM2.510 after appropriate conditioning for each sample ...". Describe the conditioning and weighing in more detail. At what humidity was the weighing done? Was $\mathrm{RH}$ measured? How long were the samples let stabilize at this $\mathrm{RH}$ before the actual weighing. The point is that quartz filters are notoriously difficult for gravimetric analyses due to their hygroscopicity.

Interactive

comment

» Thanks for the comments. Quartz fiber filter was selected for this study because we conducted the chemical analysis of water-soluble ions, metallic elements, and carbonaceous content. Before weighing, the quartz fiber filters were conditioned in a desiccator at temperatures of $20-25^{\circ} \mathrm{C}$ and relative humidity $(\mathrm{RH})$ of $35-45 \%$ for 48 hours. After conditioning, the filters were then weighed by a microbalance (Sartorius MC 5) with the precision of $1 \mu \mathrm{g}$ to determine the mass of PM2.5. The filters were stored in a weighing chamber at temperatures of $20-25^{\circ} \mathrm{C}$ and relative humidity of $35-45 \%$ (see Section 2.3 , P6, L10- L15).

(9) P3, L16-17: "PM2.5-10 samples cannot be analyzed for chemical composition since they were contaminated with the oil coated on the surface of the impactors". If the coarse-particle samples were contaminated, how can you be sure that the fine-particle filters remained clean?

» Thanks for the comments. We have revised the sentence as "In the sampler, an adapter is placed into the model TE-6001 sampler in lieu of an existing PM10 fractionator. The adapter has a plate that contains multiple impactors for collecting particles larger than PM2.5 on a slotted quartz fiber filter. PM2.5 is then passed through the impactor and collected on a quartz fiber filter. After sampling, the concentrations of PM2.5 and PM2.5-10 were determined by weighting the quartz fiber filter and the slotted quartz fiber filter, respectively. Due to the difficulty of identically dividing the slotted quartz fiber filter, we thus only analyzed the chemical compositions of PM2.5 (see Section 2.3, P6, L19-L24).

Printer-friendly version

Discussion paper 
(10) P3, L26-28, "The air quality sampling boat sailed to windward during the entire sampling voyage. Consequently, the winds were blown from the prow of the boat in order to avoid the intrusion of oil-burning particles emitted from the air quality sampling boat itself." Hard to believe. I have also sampled on a ship and it is hard to avoid wind blowing from the wrong direction during such a long time. According to Figure 1 the ship sailed partially along direct tracks and turned sharply to the right at the locations marked by the stars. Did wind direction really turn so sharply? For example, I estimated the location of the ship during the cruise leg S14C1. According to the map in Fig.1 the ship started from south of Kaohsiung City and sailed westwards on 2014-04-10. I took a random point estimatedly on the cruise route by using Google Earth, wind data from NOAAARL web page and draw a wind rose (ready.arl.noaa.gov/READY amet.php) for the date 2014-04-10. According to that wind blew from the eastern sectors between NE and SE which means from behind the ship. On the other hand, if the ship was sailing at a high enough cruise speed, the relative wind direction may have been from the clean sector. For some other locations and times the model actually does show the ship was sailing against the wind. This kind of an analysis should be shown in time series plots of true and relative wind speed and direction during the cruises. Was there any sector control?

» Thanks for the comments. In this study, the air quality sampling boat sailed continuously windward in a speed of 10 knots per hour during the sampling cruise periods. Atmospheric fine particles were sampled at the fore of the uppermost deck on the shipboard with a high-volume sampler during the voyage to prevent the interferences from the exhaust gases of the air quality sampling boat itself as the chimney of the sampling boat is located at the poop deck. After carefully checking with the records of wind speeds and wind direction in the sampling boat, it showed that the prevailing wind came mainly from the northeast $\left(25^{\circ}-53^{\circ}\right)$, in 2014-04-10, which did not blow the plume emitted from the chimney of the sampling boat to the PM2.5 sampler during the cruise sampling periods. (see P4, L3-L10).

Printer-friendly version

Discussion paper
Interactive

comment 
(11) P3, L29, "Each sampling course was arranged to collect PM2.5 for continuous 8-12 hours...". It is not quite clear whether there was only one sample taken during each course or were there more? For example during S14C4 was there only one or were there more samples taken? Explain this so that there is no ambiguity about it. And if there was more than one sample in each course then the values in the tables are averages or what?

Interactive

» Thanks for the comments. In this study, only one fine particle sample was collected during each sampling course. (see P4, L11-L12 and Table 3, P26).

(12) P4, L8 " Xiaomen site (2338'47.1"N; 11930'31.6"E)". There is obviously the degree sign $\left({ }^{\circ}\right)$ missing so that the coordinates should read $\left(23^{\circ} 38^{\prime} 47.1^{\prime \prime} \mathrm{N}\right.$; $119^{\circ} 30^{\prime} 31.6$ "E). But when I type in these coordinates in Google Earth the location seems to be not on any island but in the ocean to the southwest of the Xiaomen island and to the west of the northern part of $\mathrm{Xi}$ island. Check the coordinates and give them accurately. Another small disturbing point is that there was only this one island measurement site but throughout the text it is written "at the islands". That is not justified, especially because the Xiaomen site was really close, only $60 \mathrm{~m}$ from the sea shore (sounds like a good location, by the way), so it is definitely less polluted by local sources and much more marine than some other locations on the Penghu islands. It is misleading to write that "on the islands" the concentrations were this or that. Change the text and tables all over so that you write Xiaomen or "on the island" instead of "the islands".

» Thanks for the comments. We have corrected the coordinates of Xiaomen site $\left(23^{\circ} 33^{\prime} 41^{\prime \prime} \mathrm{N} ; 1^{\circ} 9^{\circ} 35^{\prime} 10^{\prime \prime} \mathrm{E}\right)$ and replaced "the islands" with "on the island" throughout the entire manuscript per request. (see P4, L22, and Table 2, P26)

Further, a grammar related to the islands. Use the preposition "on" not "at". Check for instance http://ell.stackexchange.com/questions/8835/in-at-or-on-an-island

Printer-friendly version

» Thanks for the comments. We have revised the preposition "at" with "on" the islands 
throughout the entire manuscript per request.

(13) P4, L19-20: "All quartz fiber filters were divided into four identical parts prior to the chemical analysis." What was the uncertainty associated with this division? Were each of these four pieces weighed also separately to find the accurate fraction of the filter that was used for each of the chemical analyses? Or was the division into four parts done only visually? Were the concentrations of the chemical species then scaled accordingly? If not, how do you know actually how big a part of the filter was used for each of the chemical analyses.

» Thanks for the comments. In this study, we divided each filter into four identical parts for analyzing the chemical composition of PM2.5. After dividing, each of the identical parts was weighed separately to make sure the accurate fraction of the filter that was used for further chemical analyses. After analyzing the chemical composition, the concentrations of the chemical species were then quantified accordingly. (see P.5, L2-L5).

(14) P4, L22 and L27. Some species were analyzed both by IC and by ICP-AES. How do these concentrations agree? For instance, at all the sites discussed in this paper $\mathrm{Na}$ is definitely only from the sea and the concentrations should be within the uncertainties the same. $\mathrm{Ca}, \mathrm{Mg}$, and $\mathrm{K}$ have also other sources. Discussion of the $\mathrm{Na}$ comparison would fit into the uncertainty section and the other comparisons to the trace element section. Make a figure with scatter plots of the concentrations of the species analyzed with these two methods.

» Thanks for the comments. The water-soluble ionic species of PM2.5 were analyzed by IC, while the metallic contents were analyzed by ICP in this study. This study aims to characterize the chemical composition (especially water-soluble ionic species) of marine fine particles (PM2.5) in the atmosphere during the highly polluted seasons and to investigate how importance of sea salt and anthropogenic particles influenced PM2.5 in the Taiwan Strait. Therefore, the discussion of chemical species in PM2.5 focused on

Printer-friendly version

Discussion paper
Interactive

comment 
water-soluble ionic species in the manuscript. Furthermore, the comparison of metallic content in PM2.5 focused on anthropogenic sources from their original region in the Taiwan Strait. A scatter diagram has been plotted in Figure 2 shown below per request. It showed that the concentrations of metallic contents ( $\mathrm{Mg}, \mathrm{K}$, and $\mathrm{Ca}$ ) analyzed by ICPAES were always higher than those of water-soluble ionic species analyzed by IC (see P5, L15-L22).

Interactive

(15) P5, L29-P6, L8. There is discussion that includes the coarse particles. Earlier, on P3, L16-17 it was written: "PM2.5-10 samples cannot be analyzed for chemical composition since they were contaminated with the oil coated on the surface of the impactors". How is it then possible you discuss here also the PM2.5-10?

» Thanks for the comments. We have revised the sentence as "In the sampler, an adapter is placed in the model TE-6001 sampler in lieu of the existing PM10 fraction. The adapter has a plate that contains multiple impactors for collecting particles larger than PM2.5 on a slotted quartz fiber filter. PM2.5 is then passed through the impactor and collected on a hi-volume quartz fiber filter. After sampling, the concentrations of PM2.5 and PM2.5-10 were then determined by weighing the quartz fiber filter and the slotted quartz fiber filter, respectively. Due to the difficulty of identically dividing the slotted quartz fiber filter, we thus solely analyzed the chemical compositions of PM2.5. (see P6, L19-L24)

(16) P7, L31-33. There are 3 equations for calculating the concentration of sea salt. Only (1) makes sense. The major ions in sea salt are $\mathrm{Na}+, \mathrm{Cl}-, \mathrm{K}+, \mathrm{Mg} 2+, \mathrm{Ca}+$, SO42- and HCO3-, of which $\mathrm{Cl}-$ may get replaced. But the other major ions are there and it does not make any sense to calculate sea salt concentration by summing only sodium and chloride (Eq.(2)). Eq. (3) on the other hand does not make sense because in sea water nitrate is far from being a conservative compound, its concentrations vary a lot, and yet its contribution is very low. For instance Seinfeld and Pandis (2006) present in their Table 8: that the nitrate concentrations vary in a range of $3 \times 10-6-2$ $\times 10-3 \%$ by weight. Measurements have shown that especially in the surface water

Printer-friendly version

Discussion paper 
nitrate concentrations are very low and one of the reasons is that nitrate is a nutrient used by marine biological organisms. Nitrate is a non-conservative tracer that is almost completely depleted in surface waters. So, it is very safe to claim that all nitrate in the filter samples analyzed in this work have come from other sources than sea water. So the only sensible equation for calculating seas salt concentration is (1). Consequently, the comparisons of the sea salt concentrations with different equations were irrelevant and should be removed from the text, tables, and figures.

» Thanks for the comments. We have removed the comparisons of the sea salt concentrations estimated by equations (2) and (3) per request. Additionally, we rearranged the Sections in the manuscript and further revised the Tables and Figures as well.

(17) P8, L6-7 " Previous studies reported that the mass of sea salts can be adopted by the sum of $\mathrm{Cl}$ - and $\mathrm{Na}+$ (equation (2)) (Chow et al., 1996; Kim et al., 2000; Tsai et al., 2011; Han et al., 2003; Virkkula et al., 2006). ..." Let us check what these papers write about calculating sea salt. Chow et al. (1996), p. 2106: "... sum of the soluble sodium and chloride to account for sea salt ..." - Kim et al. (2000) don't tell at all how to calculate sea salt mass. On p. 2037 they write: "The $\mathrm{Cl}-$ to $\mathrm{Na}+$ ratio of sea water is 1.8; however, due to the loss of $\mathrm{Cl}-$ during transport, it is normally assumed to be 1.0." But nowhere in that paper they present how to calculate sea salt mass. - Tsai et al.(2011) don't give any formula on how to calculate sea salt mass. - Han et al. (2003) is a conference abstract not available in the open literature. I could not check it and it would be better not to refer to it at all. - Virkkula et al. (2006) write on p.2: " Sea salt mass concentration was calculated from $\mathrm{Cl}-+1.47 \mathrm{Na}+$ where 1.47 is the seawater ratio of $(\mathrm{Na}++\mathrm{K}++\mathrm{Mg} 2++\mathrm{Ca} 2++\mathrm{SO} 42-+\mathrm{HCO}-) / \mathrm{Na}+$ [Bates et al., 2001; Quinn et al., 2001]..." . So, only Chow et al. (1996) write that sea salt mass could be calculated by summing up only sodium and chloride. But even if that is so in that paper it is definitely wrong, the other major sea-salt ions are present, as I wrote above.

» Thanks for the comment. We have revised the method to estimate the concentrations of sea salt in the manuscript per request (see Section 3.3.1, P10, L25-L27).

Printer-friendly version

Discussion paper 
(18) P9, L2. Eq (8) is definitely wrong. As I wrote above, nitrate is not a sea salt compound. In the aerosol it is safe to claim that all nitrate is nss.

» Thanks for the comment. We have removed the original Equation (8) and have revised Figures 3 and 4, and Table 4 in the manuscript per request (see Section 3.3.2, P11, L16-L19).

(19) P9, L6-9. All sodium and chloride in aerosol are definitely sea salt on an island 60 $\mathrm{m}$ from the ocean shore and on the ship sailing on the ocean. So the texts ss-Cl and ss-Na should be removed. The concentrations of sea salt sulfate, sea salt magnesium, sea salt kalium and sea salt calcium are all calculated simply by multiplying observed sodium concentrations with the well known ratios of the ion $X$ to sodium in seawater. The raw data for this calculation is only sodium concentration. So the ordering of ss ion concentrations in line 9 makes no sense at all. And there is an error even in that: ss $\mathrm{Ca}$ concentration should be higher than ss $\mathrm{K}$.

» Thanks for the comment. We have removed the sentence regarding the order of sea salt ion concentrations per request. (see Section 3.3.2, P11, L22-L25).

(20) P9,L29 "Chloride deficit is a process". No. Chloride deficit is a number calculated in Eq. (9). Chloride replacement is a process. " Thanks for the comment. We have revised the sentence as "Chloride replacement is the process by....." per request. (see P17, L2)

(21) P10, L19-21 " Previous study indicated that the aged nature of sea salt particles were about $150 \mathrm{~km}$ from the open sea, giving these particles enough time to react with atmospheric acidic gases (Virkkula et al., 2006). " The referenced paper presented chloride depletion at a very clean Antarctic site so it is not comparable with the Taiwan Strait. The chloride replacement process can take place in a short period and distance if the concentrations of acidic gases are high.

» Thanks for the comment. We have deleted the referred sentence (Virkkula et al., 
2006) from the manuscript per request.

(22) P11, L11. " ... crustal elements (Al, Fe, Mg, K, and $\mathrm{Ca}$ ), ..." of these $\mathrm{Mg}, \mathrm{K}$, and

$\mathrm{Ca}$ are also from sea salt. If you want to show the crustal elements only, do the sea salt correction.

» Thanks for the comments. Table 5 summarizes the concentrations of metallic elements in PM2.5. It showed that crustal and sea salt elements ( $\mathrm{Al}, \mathrm{Fe}, \mathrm{Mg}, \mathrm{K}$ and $\mathrm{Ca}$ ) were higher than those of anthropogenic elements $(\mathrm{Zn}, \mathrm{Ni}$, and $\mathrm{Pb})$. Accordingly, the sentence has been revised as, "Table 5 shows that the most abundant metallic elements of PM2.5 were crustal and sea salt elements ( $\mathrm{Na}, \mathrm{Al}, \mathrm{Fe}, \mathrm{Mg}, \mathrm{K}$, and $\mathrm{Ca}$ ) and followed by anthropogenic elements ( $\mathrm{Zn}, \mathrm{Ni}$, and Pb)" (see P12, L19-L20).

(23) P12, L17, Eq.(11) is strange. If you set in eq (10) it reduces to POC $=E C \times(O C / E C)$ pri so why don't you show it so? The method is very, very uncertain. The ratio $(\mathrm{OC} / \mathrm{EC})$ pri definitely varies according to burning material, burning temperature and other conditions. Then during transport organics condense on the particles. Your sampling sites are so far away from any sources that even the lowest OC/EC ratio at in the samples cannot represent the primary ratio at any conditions. Remove all text and results where you discuss SOC and POC. Just discuss OC, EC and particulate organic matter (POM). POM you would calculate by multipling $\mathrm{OC}$ with a factor that takes into account the amount of oxygen in organic aerosol. There are several references for this, look for them.

» Thanks for the comments. We have revised the Section 3.3.4 "Carbonaceous Contents of PM2.5 over Sea and at the Offshore Islands," per request. (see P13, L15P14, L20). Moreover, in this study, particulate organic matter (POM) was estimated by $1.6^{*}[\mathrm{OC}]$ as shown in Table 8.

\section{Referee comment 2}

Detailed comments: A. The tables and figures A1: Units need to be added to the table 


\section{5.}

» Thanks for the comments. We have added the units in Tables 3, 4, and 5 per request. (see P26-P28)

A2: Sample numbers should be added in Table 1. Actually I was confused about the sampling method. Totally how many valid filters were collected in different cruises? If the filters of PM2.5-10 were contaminated, it can be moved to the supplemented materials as there are no important results.

» Thanks for the comments. In this study, only one fine particle sample was collected during each sampling course. The number of PM2.5 samples over sea and at the offshore islands during three cruises sampling campaigns was 4,5 , and 4 , respectively (see P4, L11-L12 and Table 3, L27).

A3: Tables can contain large information than the one can be illustrated in the manuscript. The authors do not need to mention every data in the tables, but need to add some comparisons with the data in other literatures to rich the contents. Some interesting findings can be discovered during this process.

» Thanks for the comments. We have added the comparisons of the mass concentration and chemical composition data with previous literatures around the Taiwan Strait and East China Sea per request. The sentences have been revised as "Table 6 compares the concentrations of TC, OC, and EC in PM2.5 with previous studies. The total carbon concentrations were close to those at the Penghu site located at an offshore island where clean marine air can dilute PM2.5 from long-range transport, resulting in local emission accumulation and lower $\mathrm{OC}$ and EC levels at the Penghu Islands. The OC/EC ratios ranged from 3.0-7.0 on the southeastern coastline of China and from 1.9 to 2.9 on the southwestern coastline of the Taiwan Strait, respectively. The OC/EC ratios obtained from this study ranged from 2.6 to 2.8 at the Taiwan Strait which were generally lower than those reported by Chou et al., 2010 (2.6 to 2.9) and Tasi et al., 2010 (1.9 to 2.9). The comparison of OC/EC ratios showed the variation of carbona- 
ceous species analyzed with different analytical methods. The carbonaceous concentrations of particulate matter analyzed using thermal optical reflectance (TOR) and thermal optical transmittance (TOT) were generally higher than those using elemental analysis (EA)." (see P14, L12-L20). B. Logic B1: The major discussion including seven sections, and less comparison with the data over other areas, which makes the reader feel that the author is just loading the data. It is better to find some internal connection between these data and name each section following the findings. Or the author could try 3.1.1 to including some sections into one section. e.g. 3.3, 3.4 and 3.5 are all about the sea salt particles, which can be in one section.

» Thanks for the comments. We have converged and further revised the original Sections 3.3, 3.4 and 3.5 as Section 3.3 "Chemical Characteristics of PM2.5 over Sea and at the Offshore Islands" per request. (see P9, L9-P14, L20)

B2:The outline really need to be reconstructed. I often have this problem with my paper that the closely related information is not discussed until much later in the paper. Please try to discuss, at least briefly, all the relevant information on a topic at one place. Otherwise, some issues sounds like mentioned several times. Language or content can be more condensed.

» Thanks for the comments. We have rearranged the content of the Section "Results and Discussion" in the manuscript. In this Section, we discussed and interpreted the results obtained from this study in the following seven subsections. Subsection 3.1 presents the spatiotemporal variation of PM2.5 concentrations over sea and at the Offshore Islands. Subsection 3.2 introduces the transport routes during three cruise sampling campaign. Subsection 3.3 aggregates the chemical characteristic of marine fine particles during three cruise sampling campaign. Subsection 3.4 describes the distribution and source indicators of PM2.5 during three cruise sampling campaign over sea and at the offshore islands. Subsection 3.5 reconstructs the material balance equation for the gravimetric mass of PM2.5 during three cruise sampling campaign. Subsection 3.6 identifies whether the presence of certain metallic elements in PM2.5 were primar- 
ily due to natural or anthropogenic processes during the sampling cruise. Subsection 3.7 compares the chloride deficit of PM2.5 with previous studies, respectively. (see P7, L10-L18).

C. Detailed Comments C1: The weather condition should be also mentioned at first as the sampler number is limited and the reader need some general idea on the background air mass condition. " Thanks for the comments. After checking the records of wind speeds and wind direction in the sampling boat, we found that the prevailing wind came from the northeastern direction. Additionally, the backward trajectories showed that air masses blown from the north generally had higher PM2.5 concentrations than those from the south during the cruise sampling campaign. (see P4, L6-L10).

C2: Page 6 line 30 section 3.2: It should be ammonium poor area that (NH4)2SO4 is not favored. $\mathrm{NH} 4 \mathrm{HSO} 4$ is more likely.

" Thanks for the comments. We have recalculated the relationship between NO3-, SO42- and $\mathrm{NH} 4+$. NO3-, SO42- and $\mathrm{NH} 4+$ that were associated together in the same particulate system in the likely form of $\mathrm{NH} 4 \mathrm{NO} 3$, and [NH4]2SO4 or $\mathrm{NH} 4 \mathrm{HSO} 4$. Particulate phase $\mathrm{NH} 4+$ concentrations can be calculated using the stoichiometric ratios of different compounds and compared with the measurements. Nitrate is in the form of $\mathrm{NH} 4 \mathrm{NO} 3$, while sulfate is in the forms of either $(\mathrm{NH} 4) 2 \mathrm{SO} 4$ or $\mathrm{NH} 4 \mathrm{HSO} 4$ which can be estimated by equations (1) and (2).

Previous study indicated that ammonia is known to neutralize sulfuric acid irreversibly, and then nitric acid. Additionally, hydrochloric acid may react with gaseous ammonia to form ammonium chloride aerosols. However, in thermodynamic equilibrium conditions ammonium chloride is reported to be 2-3 times more volatile than ammonium nitrate (Stelson and Seinfeld, 1982) and its formation occurs later. Thus, ammonia is believed to be neutralized firstly by sulfuric acid and forms ammonium sulfate and/or ammonium bisulfate (McMurry et al., 1983; Wang et al., 2005; Du et al., 2010). In this study, we assumed that both sulfate (SO42-) and bisulfate (HSO4-) could be neutralized by am-

Printer-friendly version

Discussion paper 
monia with various portions (see P.9, L12-L24). Results obtained from the calculation of nitrate showed that the predominant inorganic compounds of PM2.5 were ammonium nitrate (NH4NO3) and ammonium bisulfate (NH4HSO4) (see P9, L26-L27).

C3: Page 8 line 9. the data obtained by equation (1) is in the middle level of these three results, however it is not a reason that "the most accurate method to estimate the sea salt concentrations was equation (1)".

» Thanks for the comment. We have revised the sentence describing the equations of sea salt estimates (see equation (3), P10, L25-L27).

C4: Page 9 line 10-15 about the anthropogenic particle influence, it can be one important topic in this manuscript. Suggest the authors make two major concern: anthropogenic source and sea salts $\mathrm{Cl}$ deficit. Besides Section 3.5 title is missing in the manuscript.

» Thanks for the comment. We have rearranged the sections according to other reviewer's suggesting and merged the original Section 3.5 into Section 3.3 in the manuscript per request. Moreover, a new Section 3.6 describes the presence of specific metallic elements in PM2.5 primarily emitted from natural or anthropogenic processes during the sampling cruises. Section 3.7 investigates and compares the chloride deficit of PM2.5 with previous studies. (see P16, L1-P18, L2)

C5: Page 12 line 30, an accurate (OC/EC)pri value used in this study should be mentioned in the manuscript. The discussion of OCEC is really poor.

» Thanks for the comment. We have removed the calculation of SOC and POC according to the suggestion from other reviewers. Moreover, we have also revised the title of the Section 3.3.4 as "Carbonaceous Contents of PM2.5 over Sea and at the Offshore Islands," per request. (see P13, L15-P14, L20)

Interactive comment on Atmos. Chem. Phys. Discuss., doi:10.5194/acp-2016-384, 2016. 